\title{
DIÁLOGOS ENTRE A GESTÃO DE \\ DOCUMENTOS E A GESTAOO DA INFORMAÇÃO: uma análise das teses e dissertações dos programas de pós-graduaçã̃o filiảos à ANCIB
}

\author{
DIALOGUES BETWEEN DOCUMENT MANAGEMENT AND \\ INFORMATION MANAGEMENT:
}

An analysis of theses and dissertations of graduate programs affiliated with ANCIB

\author{
Eliete Correia dos Santos ${ }^{1}$ \\ Noadya Tamillys Oliveira Duarte Gerbasi² \\ Vancarder Brito Sousa ${ }^{3}$ \\ Josemar Henrique de $\mathrm{Me}^{4}$
}

\begin{abstract}
RESUMO
Esta pesquisa trata-se de um estudo de caso do tipo descritivo, que busca analisar as teses e dissertações que abordam as interconexões entre as áreas da gestão de documentos (GD) e da gestão da informação (GI), no âmbito dos programas de pós-graduação relacionados à área de conhecimento da Ciência da Informação, no Brasil. Parte de discussões teóricas acerca da interdisciplinaridade entre Arquivologia e Ciência da Informação, mais especificamente sobre a possibilidade de diálogos entre gestão de documentos e gestão da informação. Entre os resultados, constatou-se que há poucas pesquisas realizadas sobre 0 tema, revelando a necessidade de se desenvolver estudos que aprofundem 0 assunto. Em relação ao conteúdo apresentado pelos pesquisadores, a perspectiva integrada foi unânime nas discussões de todos os trabalhos. Para alguns estudiosos, a GD está subordinada à GI, enquanto que para outros, essa relação não se trata de uma hierarquia, mas de áreas que se complementam. Por fim, concluiu-se que a GD e a GI são duas áreas que possuem ramos de atuação específicos, mas que podem se complementar, a fim de garantir a ocorrência dos fluxos informacionais de maneira eficaz. Palavras-chave: Gestão de documentos. Gestão da informação. Ciência da Informação. Interdisciplinaridade.
\end{abstract}

\begin{abstract}
This research is about a descriptive case study, which seeks to analyze the theses and dissertations that approach the interconnections between the areas of document management and information management, within the scope of post-graduate related in the area of knowledge of Information Science in Brazil. The thematic of the article is based on the theoretical discussions about the interdisciplinarity between Archival Science and Information Science, more specifically about the possibility of dialogues between document management and information management. Among the results, it was found that there are a few researches done on the subject, revealing the need to develop studies that deepen the subject. In relation to the content presented by the researchers, the integrated perspective was unanimous in the discussions of all the works. For some scholars, document management is subordinate to information management, while for others, this relationship is not a hierarchy, but areas that complement each other. Finally, it was concluded that document management and information management are two areas that have specific branches, but they can complement each other in order to guarantee the occurrence of information flows in an efficient way.

Keywords: Document management. Information management. Information Science. Interdisciplinarity.
\end{abstract}

Artigo recebido em 20/02/2019 e aceito para publicação em 15/03/2019

1 Doutora em Linguística pela Universidade Federal da Paraíba, Brasil. Professora da Universidade Estadual da Paraíba, Brasil. Docente colaboradora do Programa de Pós-Graduação em Linguagem e Ensino da Universidade Federal de Campina Grande, Brasil. Líder do grupo de pesquisa CNq Arquivologia e Sociedade. E-mail: professoraeliete@hotmail.com.

2 Mestre em Ciência da Informação pela Universidade Federal da Paraíba, Brasil. Bacharel em Comunicação Social pela Universidade Federal da Paraíba, Brasil. E-mail: noadyadi@gmail.com.

3 Doutor em Sociologia pelo Programa de Pós-Graduação em Sociologia da Universidade Federal da Paraíba, Brasil. Professor do Departamento de Ciências Biológicas e do Curso de Arquivologia da Universidade Estadual da Paraíba, Brasil. E-mail: vancarder@hotmail.com.

4 Doutor em Documentação pela Universidade do Porto, Portugal. Professor do curso de Bacharelado em Arquivologia da Universidade Estadual da Paraíba, Brasil. E-mail: josemarhenrique@gmail.com. 


\section{INTRODUÇÃO}

0 ambiente informacional pode envolver informações do tipo orgânica e/ou não-orgânica. Em se tratando de organizações, esses dois tipos de informações são importantes para 0 bom funcionamento dos fluxos informacionais. Logo, desenvolver pesquisas que busquem analisar as suas peculiaridades é imprescindível para o conhecimento e 0 aprofundamento dos aspectos que os compõem.

No Brasil, a Ciência da Informação $(\mathrm{Cl})$ tem abordado essa temática por meio de duas correntes de estudo, a saber, gestão de documentos (GD) e gestão da informação (GI). A primeira corrente centraliza seus esforços em pesquisas que analisam os fluxos constituídos de informações orgânicas (tais informações são objetos de estudo da Arquivologia, sendo compreendidas como informações sociais produzidas, recebidas e ou acumuladas pelas instituições, sejam públicas, sejam privadas ou por pessoas físicas na consecução de suas funções), enquanto que a segunda corrente (GI) tem realizado pesquisas que permeiam os dois tipos de informações.

No entanto, a interdisciplinaridade entre essas áreas tem sido alvo de discussões no campo científico. Um estudo realizado por Vitoriano (2017), cujo objetivo era analisar a presença do tema da gestão da informação em artigos de temáticas arquivística, revelou que os temas da Gl na Arquivologia são pouco recorrentes. Além disso, na maioria dos casos analisados, a discussão é realizada em torno de questões arquivísticas, com baixo nível de relação com tópicos da $\mathrm{Cl}$.

Sendo assim, no intuito de aprofundar o conhecimento acerca dessas questões mencionadas, esta pesquisa busca compreender como a Ciência da Informação tem abordado as interconexões entre GD e Gl? Para responder a esse questionamento, traçou-se o seguinte objetivo geral: analisar as teses e dissertações que abordam as interconexões entre as áreas da gestão de documentos e da gestão da informação, no âmbito dos programas de pós-graduação relacionados à área de conhecimento da Ciência da Informação no Brasil.

Os resultados dessa pesquisa serão relevantes para a Ciência da Informação e suas áreas correlatas, uma vez que viabiliza o aprofundamento dos estudos referentes ao seu conhecimento. Destarte, por meio desse estudo foi possível observar como esses temas estão sendo abordados pelos cientistas e, concomitantemente, fazer apontamentos de possíveis ações conjuntas entre GD e Gl, tendo em vista o desenvolvimento dos fluxos informacionais nas organizações. 


\section{GESTÃO DE DOCUMENTOS}

A gestão de documentos tem como principal alicerce os paradigmas e os princípios oriundos da Arquivologia que, por sua vez, tem como objetivo estudar os fenômenos que envolvem o contexto documental das organizações desde a sua produção até a sua destinação final. A Arquivologia, enquanto área institucionalizada de ensino e pesquisa no Brasil, é classificada como uma das subáreas da Ciência da Informação. No entanto, enquanto objeto de estudo, a sua relação com a Ciência da Informação tem sido pauta de discussões epistemológicas da área, as quais buscam responder a seguinte indagação: a Arquivologia é considerada uma disciplina autônoma ou uma subárea da Cl?

Jardim (2011) sintetizou esse debate explicando que a Arquivologia é uma disciplina que tem como característica a interdisciplinaridade, a qual transita entre pelo menos três vertentes: um campo autônomo; uma disciplina que constitui uma subárea da Ciência da Informação; e uma disciplina científica em permanente construção, que é dotada de autonomia, mas que também possui relações interdisciplinares com a história, a administração, a Ciência da Informação, a biblioteconomia, a museologia, a sociologia, entre outras. Sendo assim, a gestão de documentos também pode ser considerada interdisciplinar, uma vez que seus estudos resultam de uma disciplina com essa mesma característica.

Em relação ao surgimento da GD, Indolfo (2007) explica que seu principal contexto envolve uma dimensão administrativa, relacionada aos Estados Unidos, a partir de 1940. A autora afirma que, com 0 fim da Segunda Guerra, foi surgindo uma série de problemas relacionados à produção e ao acúmulo de documentos, levando à criação de algumas comissões e a expedição de atos legislativos específicos sobre o problema. As ações das Comissões Hoover (1947 e 1953, respectivamente) e a Federal Records Act (1950), por exemplo, resultaram em uma determinação que passou a exigir 0 records management program nos organismos governamentais da época.

A partir desse cenário político e administrativo, passou-se a elaborar vários modelos de gestão, os quais buscavam encontrar maneiras eficazes de se gerir as práticas relacionadas aos documentos. Esse modo de pensar acerca dos documentos se expandiu respeitando as especificidades de cada país e hoje vai além do contexto político e da esfera das instituições públicas. Atualmente a GD tem sido pensada e aplicada nos mais variados tipos de organização (pública, privada ou terceiro setor), desde que se enquadrem nos princípios estabelecidos e defendidos pela Arquivologia. 
No que tange ao conceito de GD, Indolfo (2007) elucida que não se pode falar em um modelo único e de aplicação universal, uma vez que a sua elaboração envolve fatores histórico e institucional específicos, além de refletirem as tradições arquivísticas de sua época. Na concepção de Jardim (1987), a GD envolve todo o ciclo de existência dos documentos, desde sua produção até a eliminação ou seu recolhimento para o arquivo permanente, contemplando um conjunto de atividades que se desenvolvem nas fases corrente e intermediária. É importante destacar que no Brasil a GD ganhou espaço na Lei Federal 8.159 de 08 de Janeiro de 1991 que dispõe sobre a política nacional de arquivo.

Heredia Herrera (1998) também apresenta um conceito ressaltando que o papel da GD refere-se à manutenção do ciclo de vida dos documentos, o qual será viabilizado por meio dos seguintes aspectos: coleta, identificação, avaliação, eliminação, conservação, organização, descrição e disseminação dos documentos. Roncaglio, Roncaglio, Décio e Silvana (2004) destacam o papel estratégico da GD na constituição do acervo arquivístico, o qual viabiliza a definição do ciclo vital dos documentos, estabelecendo os que serão recolhidos para guarda permanente e os que serão eliminados.

Quanto às atividades da GD, Reis e Barros (2017) afirmam que elas resultam de um conjunto de funções que vão desde a criação do documento à sua destinação final, são elas: identificação, classificação e avaliação. Mas é importante ressaltar que a as atividades da GD tem como foco a produção de informações orgânicas registradas, ou seja, são documentos que possuem relações intrínsecas com o seu produtor. Nesse aspecto, Calderón, Cornelsen, Pavezi e Lopes (2004) explanam que as informações arquivísticas são de caráter contábil/financeira, pessoal e administrativa, que se encontram inseridas em diferentes espécies documentais.

Sendo assim, o conjunto de definições e conceitos apresentados possibilita inferir que os documentos e a sua informação orgânica merecem uma atenção especial no contexto organizacional, e a Arquivologia, por meio da gestão de documentos, oferece subsídios teóricos e práticos que permitirão realizar uma análise minuciosa desse material, a fim de se evitar o excesso de informações e facilitar 0 seu acesso por parte dos usuários.

\section{GESTÃO DA INFORMAÇÃO}

A gestão da informação envolve um conjunto de conceitos e práticas que lidam com a formação e a continuidade dos processos informacionais, em seus mais variados contextos sociais. Enquanto objeto de estudo, a GI atualmente é considerada uma das correntes teóricas (ou subáreas) da Ciência 
DIÁLOGOS ENTRE A GESTÃO DE DOCUMENTOS E A GESTÃO DA INFORMAÇÃO: uma análise das teses e dissertações...

da Informação (ARAÚJO, 2014), cujas discussões envolvem não apenas o conteúdo informacional em si, mas também os contextos organizacionais e sua influência na cultura informacional (ARAÚJO, 2014).

Quanto às origens da gestão da informação, Silva, Moreira e Monteiro (2014) explanam que estão relacionadas à documentação, uma disciplina apresentada e defendida por Paul Otlet, em 1934, cujo objetivo era criar um repositório bibliográfico universal, no qual estivesse registrado todo 0 conhecimento humano. Essa disciplina envolvia atividades de organização, armazenamento, recuperação e acesso à informação, o que pode ser caracterizada como o início da gestão da informação.

Atualmente, um dos principais aspectos da GI giram em torno dos recursos informacionais e suas mais variadas formas de aquisição e uso (PONJUÁN DANTE, 2004, TARAPANOFF, 2006, SANTOS; VALENTIM, 2014). Segundo Ponjuán Dante (2004), a GI é um processo que envolve atividades de aquisição, implementação e uso de recursos básicos que visam potencializar o manuseio de informações.

Concomitantemente, Tarapanoff (2006) esclarece que identificar e potencializar recursos informacionais de uma organização é o principal objetivo da gestão da informação e, além disso, a autora acrescenta que é dever da GI auxiliar a capacidade de informação dessa organização, por meio de processos que os ensinarão a aprender e adaptar-se a mudanças ambientais. Para Santos e Valentim (2014), esses recursos são oriundos de fontes formais existentes nos distintos setores de uma organização e o papel da GI consiste justamente em mapear, organizar e disseminar isso de maneira adequada para os sujeitos da organização.

Além dos aspectos citados anteriormente, a GI também precisa lidar com os seguintes aspectos da organização: a) seus diferentes tipos de informações; b) a dinâmica dos fluxos informacionais existentes; c) o ciclo de vida de cada informação; e d) a cultura informacional (PONJUÁN DANTE, 2004). Nessa perspectiva, Barbosa (2008) destaca que a gestão da informação trabalha com o conhecimento explícito organizacional, ou seja, ela lida com o universo de documentos, dos mais diversos tipos, os quais são produzidos, armazenados e utilizados em um contexto organizacional.

Por fim, Santos e Valentim (2014) apresentam uma explanação que converge com a discussão apresentada até aqui, destacando o papel crucial da Gl, que é suprir as necessidades informacionais dos sujeitos, tendo em vista um ambiente organizacional mais dinâmico, com processos que vão desde a geração até 0 uso da informação.

Os diálogos apresentados possibilitam inferir que é por meio da GI que a organização processa os conteúdos relevantes para o seu negócio, eliminando o excesso de informações e suprindo as 
necessidades existentes, o que viabilizará fluxos informacionais mais dinâmicos e eficazes. Para isso, é preciso considerar os diferentes tipos de documentos, os recursos disponíveis e a cultura informacional que é cultivada nos ambientes da organização.

\section{PROCEDIMENTOS METOdOLÓGICOS}

Para atingir o objetivo geral desta pesquisa ao analisar as teses e dissertações que abordam as interconexões entre as áreas da gestão de documentos e da gestão da informação, no âmbito dos programas de pós-graduação relacionados à área de conhecimento da Ciência da Informação no Brasil, traçou-se os seguintes objetivos específicos: a) verificar a frequência das teses e dissertações que relacionam a $\mathrm{GD}$ e a $\mathrm{Gl}$; b) mapear os programas que mais realizam teses e dissertações sobre 0 diálogo entre essas áreas; c) identificar as características dos conteúdos das teses e dissertações que versam sobre a temática desse estudo.

Caracteriza-se como um estudo de caso do tipo descritivo, utilizando-se das abordagens quantitativa e qualitativa para tratar os dados, por meio de um estudo do tipo documental. Envolveu os Programas de Pós-Graduação que integram a área de conhecimento da Ciência da Informação no Brasil, pelo fato de desenvolverem estudos referentes à Arquivologia e à Gestão da Informação. Para isso, foram analisadas as teses e as dissertações dos programas que são associados à Associação Nacional de Pesquisa e Pós-Graduação em Ciência da Informação (ANCIB), por se tratar de uma das principais instituições que acompanham o desenvolvimento da $\mathrm{Cl}$ no país.

Durante o processo de pesquisa no site da ANCIB, identificou-se que há 16 programas em seu rol de associados (na época da respectiva busca), a saber: PPGCI da Universidade Federal do Rio de Janeiro (UFRJ), PPGCI da Universidade de São Paulo (USP), PPGCI da Universidade Federal de Minas Gerais (UFMG), Programa de Pós-Graduação em Gestão \& Organização do Conhecimento (UFMG), PPGCI da Universidade Federal da Paraíba (UFPB), PPGCI da Universidade de Brasília (UnB), PPGCI da Universidade Estadual Paulista Júlio de Mesquita Filho (UNESP), PPGCI Universidade Federal da Bahia (UFBA), PPGCI da Universidade Federal de Santa Catarina (UFSC), PPGCI da Universidade Federal Fluminense (UFF), PPGCI da Universidade Federal de Pernambuco (UFPE), PPGCI Universidade Estadual de Londrina (UEL), Programa de Pós-Graduação em Memória Social da Universidade Federal do Estado do Rio de Janeiro (UNIRIO), Programa de Pós-Graduação em Museologia e Patrimônio (UNIRIO), PPGCI da Universidade do Estado de Santa Catarina (UDESC) 
DIÁLOGOS ENTRE A GESTÃO DE DOCUMENTOS E A GESTÃO DA INFORMAÇÃO: uma análise das teses e dissertações...

e Programa de Pós-Graduação em Ciência da Comunicação e Informação, da Universidade Federal do Rio Grande do Sul (UFRGS).

Para a coleta dos dados, foram empregadas como fontes de informação, a Biblioteca Digital Brasileira de Teses e Dissertações (BDTD) e os repositórios institucionais das universidades (quando não tinham seus trabalhos disponíveis na BDTD). A busca contemplou as pesquisas que foram defendidas entre os anos de 2006 a 2017. A escolha do recorte temporal se deu devido ao fato de que, nos anos anteriores a 2006, algumas universidades não depositaram pesquisas de pós-graduação em suas plataformas, tendo em vista que a obrigatoriedade do depósito digital só ocorreu após a publicação da Portaria $n^{0} 13$ da CAPES (2006). Com isso, as universidades foram obrigadas a disponibilizar, em seus arquivos digitais, os trabalhos defendidos a partir de março de 2006.

0 universo da pesquisa é composto pelo total de teses e dissertações desenvolvidas dentro do recorte temporal estabelecido. No entanto, não foi possível obter essa informação durante o período de coleta, uma vez que nem todos os programas disponibilizaram esse dado em seus repositórios e/ ou sites institucionais. No que tange à amostra, considerou-se apenas os estudos que abordavam a temática em questão, possibilitando resgatar um total de 5 dissertações (durante o processo de coleta, não foram identificadas pesquisas de doutorado, conforme será explicitado na apresentação e discussão dos resultados).

No primeiro momento da pesquisa, foi realizada uma busca no portal da ANCIB, no intuito de identificar os programas que estavam associados. No segundo momento, verificou-se quais desses programas continham pesquisas disponíveis na BDTD ou em seus repositórios institucionais. Por fim, no terceiro momento, foram identificados e analisados os trabalhos que se adequavam ao objetivo da pesquisa.

A busca nas bases de dados foi realizada por meio dos termos gestão de documentos, gestão arquivística, gestão documental e gestão da informação, nos seguintes campos: título, resumo, palavraschave, sumário e, quando necessário, o trabalho por completo. Após a identificação dos termos, foram realizadas leituras e fichamentos das seções ou subseções (introdução, referencial teórico, conclusão, etc.), que apresentavam alguma discussão sobre a temática. Para isso, utilizou-se um formulário como instrumento de coleta de dados, que continha os seguintes metadados: autor, título, programa de pósgraduação, ano, tipo de pesquisa (dissertação ou tese) e fichamento da discussão do autor.

Para a análise dos dados, utilizou-se a técnica de análise de conteúdo, que, segundo Bardin (2011), trata-se de um conjunto de procedimentos sistemáticos e objetivos de descrição do conteúdo 
das mensagens, resultando em indicadores quantitativos ou não, que possibilitam inferir conhecimentos relativos às condições de produção/recepção dessas mensagens.

0 processo de explicitação, sistematização e expressão do conteúdo das mensagens foi organizado em três etapas, a saber: a) pré-análise: equivaleu à organização do material da pesquisa, por meio da separação dos trabalhos e, posteriormente, do preenchimento do formulário; b) exploração do material: contemplou as etapas de leitura e fichamento dos trechos que abordavam a temática da pesquisa; c) interpretação e inferência: nessa fase, foi possível analisar o posicionamento dos autores quanto às áreas da GD e Gl.

\section{APRESENTAÇÃO E DISCUSSÃO DOS RESULTADOS}

A partir dos objetivos traçados, dos métodos estabelecidos para a pesquisa e do referencial teórico acerca da gestão de documentos e da gestão da informação, foi possível identificar e analisar as pesquisas dos programas de pós-graduação da CI no Brasil, conforme mostra a Tabela 1 a seguir.

Tabela 1 - Dissertações que apresentam interlocuções entre a gestão de documentos e a gestão da informação

\begin{tabular}{l|l|c|c|c}
\hline \multicolumn{1}{c|}{ Autor } & \multicolumn{1}{c|}{ Título } & Programa & Ano & Tipo \\
\hline Carvalho, & $\begin{array}{l}\text { O impacto da gestão de } \\
\text { documentos no processo de } \\
\text { produção digital da TV Senado }\end{array}$ & PPGCI/UNB & 2010 & D \\
\hline Silva, & $\begin{array}{l}\text { Gestão de documentos, } \\
\text { informação e conhecimento: a } \\
\text { óptica dos gestores do serviço } \\
\text { natrícia Andrade } \\
\text { da } \\
\text { comercial (SENAC-DF) }\end{array}$ & PPGCI/UNB & 2011 & D \\
\hline $\begin{array}{l}\text { Nascimento, } \\
\text { Natália Marinho do do }\end{array}$ & $\begin{array}{l}\text { Tipos documentais e fluxos de } \\
\text { informação como subsídios } \\
\text { para o processo decisório em } \\
\text { ambientes organizacionais }\end{array}$ & PPGCI/UNESP & 2014 & D \\
\hline Hamad, & $\begin{array}{l}\text { Análise da gestão da informação } \\
\text { do núcleo de educação especial } \\
\text { (NEDESP/UFPB). }\end{array}$ & PPGCI/UFPB & 2016 & D \\
Hana Pachu & $\begin{array}{l}\text { Diretrizes para uma política } \\
\text { integrada de gestão documental, } \\
\text { da informação e do conhecimento } \\
\text { no SEBRAE Paraíba }\end{array}$ & PPGCI/UFPB & 2017 & D \\
\hline Lima, \\
Ediene Souza de
\end{tabular}

Fonte: Dados da pesquisa (2018). 
DIÁLOGOS ENTRE A GESTÃO DE DOCUMENTOS E A GESTÃO DA INFORMAÇÃO: uma análise das teses e dissertações...

De acordo com os dados apresentados na Tabela 1, observa-se que 5 dissertações abordaram a temática desse estudo. No entanto, não houve pesquisas desenvolvidas em nível de doutorado. Entre os programas de pós-graduação que subsidiaram esses estudos, estão: PPGCI/UNB, PPGCI/ UNESP e PPGCI/UFPB. Quanto ao período em que as dissertações foram realizadas, percebeu-se que se iniciou no ano de 2010, tornando-se recorrente nos anos posteriores e encerrando-se em 2017 (ano estabelecido para o final do recorte temporal).

A partir desses resultados, é possível inferir que os pesquisadores da Ciência da Informação têm realizado estudos que abordam a relação entre GD e GI. No entanto, levando em consideração o total de teses e dissertações que já foram desenvolvidas pela $\mathrm{Cl}$, nota-se que há poucas pesquisas especificamente sobre esse tema. Destarte, durante o procedimento de coleta, não foi possível identificar nenhuma tese, algo que é essencial para uma área de conhecimento, uma vez que esses estudos viabilizam o aprofundamento e a renovação dos paradigmas relacionado à Ciência da Informação.

Os dados também revelam que são poucos os programas de pós-graduação que possuem estudos sobre o tema. Em um total de 16 programas associados à ANCIB, apenas quatro desenvolveram pesquisas relacionando gestão de documentos e gestão da informação. Entre esses quatro programas identificados, apenas o PPGCI/UFPB e o PPGCI/UNB apresentaram mais de uma pesquisa realizada. Trata-se de uma realidade que necessita de atenção por parte desses programas, já que são essas as instituições que possuem a incumbência de fomentar e desenvolver as teses e dissertações sobre a Ciência da Informação.

No que concerne ao período em que as dissertações foram desenvolvidas, percebese que essas abordagens sobre GI e GD foram realizadas recentemente (levando em consideração o recorte temporal da pesquisa, que foi de 2006 a 2017). A partir de 2010, os pesquisadores começaram a realizar estudos com foco em uma abordagem mais interligada sobre essas duas áreas. Nos anos seguintes, algumas dissertações também seguiram essa mesma linha temática, revelando que houve uma reincidência quanto ao desenvolvimento desses estudos.

Em relação ao posicionamento dos pesquisadores sobre a integração entre as áreas, os dados mostram que houve uma concordância no que tange à necessidade de se abordar essas duas áreas de maneira dialógica, conforme é apresentado nos fichamentos do Quadro 1 a seguir. 
Quadro 1 - Inferência dos autores quanto às áreas GD e Gl

\begin{tabular}{|c|c|}
\hline Autor & Discussão apresentada pelo autor \\
\hline $\begin{array}{l}\text { Carvalho, } \\
2010\end{array}$ & $\begin{array}{l}\text { A execução das atividades nas emissoras de televisão demanda interações } \\
\text { informativas em todos os personagens envolvidos no processo. A inserção } \\
\text { de atividades de gestão de documentos no fluxo de trabalho dos produtores } \\
\text { da TV Senado, em ambiente de produção digital, cria condições para que a } \\
\text { emissora consolide a articulação entre seus diversos setores. É necessário, } \\
\text { portanto, uma abordagem integrada quanto à gestão de documentos e da } \\
\text { gestão da informação, que considere todas as etapas de trabalho, enfatizando } \\
0 \text { ambiente da informação em sua totalidade. (p. 65-66) }\end{array}$ \\
\hline Silva, 2011 & $\begin{array}{l}\text { Mediante as perspectivas teóricas, análise do estudo de caso e a percepção dos } \\
\text { gestores é possível afirmar que a Gestão de Documentos poderia destacar-se } \\
\text { no contexto organizacional como ferramenta de gestão que subsidia a Gestão } \\
\text { da Informação e proporcionar a criação de novos conhecimentos. (p. 8) }\end{array}$ \\
\hline $\begin{array}{l}\text { Nascimento, } \\
2014\end{array}$ & $\begin{array}{l}\text { Assim como os fluxos informacionais perpassam a gestão da informação, } \\
\text { obviamente perpassam a gestão documental, visto que ela é parte da gestão da } \\
\text { informação. [...] para definir os tipos documentais é importante mapear o fluxo } \\
\text { informacional, atividade/objeto da GI. (p. 59) }\end{array}$ \\
\hline Hamad, 2016 & $\begin{array}{l}\text { Como resultados, foi identificado que não existe uma gestão da informação } \\
\text { estruturada no NEDESP, que as informações não são sistematizadas e que } \\
\text { não há um processo de monitoramento e avaliação para adequar as práticas } \\
\text { informacionais utilizadas. Para auxiliar o processo de Gl do NEDESP foram } \\
\text { propostas práticas de gestão da informação, passando pela gestão de } \\
\text { documentos, gestão por processos, pela sistematização do levantamento de } \\
\text { dados do Núcleo e pelo Portal Corporativo. (p. } 7 \text { ) }\end{array}$ \\
\hline Lima, 2017 & $\begin{array}{l}0 \text { estudo apresenta diretrizes norteadoras para uma política integrada de } \\
\text { Gestão Documental (GD), da Informação (GI) e do Conhecimento (GC) } \\
\text { no Sebrae na Paraíba. Os resultados obtidos remetem a formulação das } \\
\text { seguintes diretrizes: alinhar os planos da documentação, da informação e do } \\
\text { conhecimento com as estratégias da organização; desenvolver a valorização } \\
\text { dos ativos intangíveis; instituir uma comissão de GD, GI e GC; estimular a } \\
\text { cultura informacional e do conhecimento; promover a capacitação do cliente } \\
\text { interno e externo como foco na apreensão dos processos de GD, GI e GC; } \\
\text { implementar a infraestrutura de Tecnologias da Informação e Sistemas de } \\
\text { Informação incorporadas à GD, GI e GC; e elaborar uma política integrada de } \\
\text { GD, GI e GC. (p. 8) }\end{array}$ \\
\hline
\end{tabular}

Fonte: Dados da pesquisa (2018).

Conforme mostra os dados do Quadro 1, no estudo realizado por Carvalho (2010), constatou-se que a gestão da informação envolve todo o ciclo informacional da organização, inclusive os documentos produzidos em suas unidades. Nesse sentido, a integração entre as duas áreas foi uma das principais necessidades identificadas pelo pesquisador. Seguindo essa perspectiva, Silva (2011) apresentou uma conclusão semelhante, concluindo que a GD pode subsidiar a GI como uma ferramenta de gestão. 
DIÁLOGOS ENTRE A GESTÃO DE DOCUMENTOS E A GESTÃO DA INFORMAÇÃO: uma análise das teses e dissertações...

Tal realidade também foi constatada por Hamad (2016), quando analisou a gestão da informação do Núcleo de Educação Especial da Universidade Federal da Paraíba (NEDESP/UFPB). A autora conclui que, para auxiliar o processo de GI nessa organização, serão necessárias algumas práticas de gestão da informação, as quais necessitariam envolver a gestão de documentos, gestão por processos, sistematização do levantamento de dados do Núcleo e seu portal corporativo.

A abordagem integrada de GD e GI também foi discutida na dissertação de Lima (2017), que teve como universo a filial do Sebrae na Paraíba. Especificamente nesse caso, a pesquisadora ainda acrescentou outra dimensão a ser considerada nas organizações, que é a gestão do conhecimento (GC). 0 estudo apresenta diretrizes norteadoras para uma política integrada de gestão de documentos, gestão da informação e gestão do conhecimento.

Lima (2017) destaca que, no âmbito do Sebrae, é preciso trabalhar essas três áreas de maneira síncrona, a fim de atingir os objetivos e metas traçadas pela organização. Os resultados mostram uma convergência nas diretrizes que devem ser tomadas. Na Arquivologia, por exemplo, a criação de uma comissão é imprescindível para determinar os valores e os prazos de guarda dos documentos. As tecnologias e os sistemas de informação também são essenciais para o trabalho do arquivista. No Sebrae, a pesquisadora constatou que esses mesmos aspectos podem ser planejados em consonância com as diretrizes da gestão da informação e do conhecimento.

Outro ponto destacado por Lima (2017) é o estabelecimento de uma política integrada entre essas três áreas. Nota-se que com essa diretriz estabelecida, será possível guiar a organização tendo como base os critérios estabelecidos em sua política. Logo, os objetivos e as metas da organização serão trabalhados de maneira integrada pela GD, GI e GC.

Nascimento (2014), por sua vez, pesquisou sobre os tipos documentais e fluxos de informação como subsídios para o processo decisório em ambientes organizacionais e concluiu que a GD é parte integrante da GI, uma vez que a gestão de documentos é constituída por meio dos fluxos informacionais formais.

Segundo Ponjuán Dante (2004), o estudo desses fluxos é atividade da gestão da informação. Logo, tendo como base essa linha de abordagem, pode-se inferir que a relação intrínseca entre GD e GI é, principalmente, baseada no aspecto dos fluxos informacionais, uma vez que essas duas áreas têm como objetivo comum potencializar esses fluxos, o qual envolve informações orgânicas e nãoorgânica. 


\section{CONSIDERAÇÕES FINAIS}

A análise das teses e dissertações dos PPGCl's do Brasil resultou em um conjunto de informações acerca das abordagens teóricas e práticas sobre a relação entre GD e Gl. Entre os resultados, observou-se que, apesar de haver algumas dissertações sobre o tema, trata-se de um cenário ainda incipiente, com poucas pesquisas e nenhuma tese, revelando a necessidade de se desenvolver estudos que aprofunde 0 assunto.

No que concerne à quantidade dos programas de pós-graduação que subsidiaram as pesquisas, também foi possível inferir que são poucos, se comparado ao total de PPGCl'S. Por outro lado, notou-se que, durante o período estipulado pelo recorte temporal, pesquisas com esse tema foram recorrentes nos anos posteriores, mostrando que houve uma continuidade das discussões em questão. Ainda foi possível observar que esse tipo de abordagem é recente, uma vez que as primeiras dissertações foram datadas a partir de 2010.

Em relação ao conteúdo apresentado pelos pesquisadores, a perspectiva integrada dessas duas áreas foi unânime nas conclusões de todas as dissertações. Além disso, percebeu-se que a relação entre GD e GI não se trata de hierarquias, mas de áreas que se complementam no contexto das organizações. Por outro lado, na pesquisa de Nascimento (2014), a gestão de documentos foi apresentada como parte integrante da gestão da informação.

Sendo assim, por meio da análise dessas dissertações, pode-se inferir que a GD e Gl são duas áreas que possuem ramos de atuação específicos, mas que podem se complementar, a fim de garantir a ocorrência dos fluxos informacionais de maneira eficaz. Trata-se de um resultado que corrobora com um dos vieses apontados por Jardim (2011), ao postular que a Arquivologia é uma disciplina científica em permanente construção e interdisciplinar. Nesse quesito, a Ciência da Informação, enquanto área institucional de conhecimento no país, pode ser capaz de relacionar e aprofundar esses estudos, por intermédio dos seus programas de pós-graduação.

Destarte, além dos resultados empíricos apontados, essa pesquisa também possibilitou suscitar a seguinte reflexão: seria então essa interconexão entre gestão de documentos e gestão da informação mais um dos diálogos existentes entre a Arquivologia e as demais temáticas abordadas pela Ciência da Informação? Trata-se de uma indagação que ainda não se desvendou por completo, mas, que pelo menos, torna visível uma proposição que não pode ser ignorada pela $\mathrm{Cl}$ e pela Arquivologia. 
DIÁLOGOS ENTRE A GESTÃO DE DOCUMENTOS E A GESTÃO DA INFORMAÇÃO: uma análise das teses e dissertações...

Há de se convir que esse estudo possui algumas limitações quanto ao seu universo, uma vez que a pesquisa não contemplou os trabalhos que ainda não estão em suporte digital. Com isso, recomenda-se que sejam realizadas outras pesquisas que contemplem o maior número possível de discussões realizadas sobre esse tema, com o intuito de se obter uma análise ainda mais elucidada acerca das possíveis relações entre GD e Gl.

\section{REFERÊNCIAS}

ARAÚJJ, C. A. A. de. Fundamentos da Cl: correntes teóricas e o conceito de informação.

Perspectivas em Gestão \& Conhecimento, v. 4, n. 1, p. 57-79, jan./jun., 2014. Disponível em: http:// periodicos.ufpb.br/ojs/index.php/pgc/article/view/19120. Acesso em: 22 mar 2018.

BARDIN, L. Análise de Conteúdo. São Paulo: Edições 70, 2011.

CALDERÓN, W. R.; CORNELSEN, J. M.; PAVEZI, N.; LOPES, M. A. 0 processo de gestão documental e da informação arquivística no ambiente universitário. Ci. Inf., v. 33, n. 3, p. 97-104, set./dez, 2004. Disponível em: http://www.scielo.br/pdf/ci/v33n3/a11v33n3.pdf. Acesso em: 22 mar. 2018.

CARVALHO, E. de S. 0 impacto da gestão de documentos no processo de produção digital da TV Senado. 2010. 249 f. Dissertação (Mestrado em Ciência da Informação). Universidade de Brasília, Brasília, DF, Brasil. 2010. Disponível em: http://repositorio.unb.br/handle/10482/7196. Acesso em: 22 mar. 2018.

HAMAD, H. P. Análise da gestão da informação do núcleo de educação especial (NEDESP/UFPB). 2016. 127 f. Dissertação (Mestrado em Ciência da Informação). Universidade Federal da Paraíba, João Pessoa, PB, Brasil. 2016. Disponível em: http://tede.biblioteca.ufpb.br:8080/handle/tede/8311. Acesso em: 24 mar. 2018.

HEREDIA HERRERA, A. El debate sobre la gestión documental. Métodos de Información, v. 5, p. 3036, 1998.

INDOLFO, A. C. Gestão de documentos: uma renovação epistemológica no universo da Arquivologia. Arquivística.net, 3 (2), p. 28-60, 2007. Disponível em: http://www.brapci.inf.br/_repositorio/2011/06/ pdf_59336b505e_0003553.pdf. Acesso em: 5 jun. 2018.

JARDIM, J. M. O conceito e a prática da gestão de documentos. Acervo: Revista do Arquivo Nacional, V. $2, n^{0} 2$, p. $35-42,1987$.

JARDIM, J. M. A pesquisa como fator institucionalizante da Arquivologia enquanto campo científico no Brasil. In MARQUES, A. A. da C; RONCAGLIO, C; RODRIGUES, G. M. (Orgs.). A formação e a pesquisa em Arquivologia nas universidades públicas brasileiras. Brasília: Thesaurus, 2010. p. 53-75.

LIMA, E. S. de. Diretrizes para uma política integrada de gestão documental, da informação e do conhecimento no SEBRAE Paraíba. 2017. 149 f. Dissertação (Mestrado em Ciência da Informação). 
Universidade Federal da Paraíba, João Pessoa, PB, Brasil. 2017. Disponível em: http://tede.biblioteca. ufpb.br:8080/handle/tede/9709. Acesso em: 3 mai. 2018.

NASCIMENTO, N. M. do. Tipos documentais e fluxos de informação como subsídios para 0 processo decisório em ambientes organizacionais. 2014. 191 f. Dissertação (Mestrado em Ciência da Informação). Universidade Estadual Paulista, Faculdade de Filosofia e Ciências de Marília, Marília, SP, Brasil, 2014. Disponível em: http://hdl.handle.net/11449/149973. Acesso em 22 mar. 2018.

PONJUÁN DANTE, G. Gestión de la información: dimensiones e implementación para el éxito organizacional. Rosario: Nuevo Parhadigma, 2004.

REIS, L. S.; BARROS, T. H. B. Arquivos semiativos: um estudo dos marcos teórico-conceituais na gestão de documentos por meio de um estudo metateórico. Ágora, 27 (55), p. 368-400, 2017. Disponível em: https://agora.emnuvens.com.br/ra/article/view/665. Acesso em: 22 mar. 2018.

RONCAGLIO, C.; DÉCIO R. S.; SILVANA de F. B. Arquivos, gestão de documentos e informação. Encontros Bibli, ed. esp., 1-14, 2004.

SANTOS, C. D.; VALENTIM, M. L. P. As interconexões entre a gestão da informação e a gestão do conhecimento para o gerenciamento dos fluxos informacionais. Perspectivas em Gestão \& Conhecimento, 4 (2), p. 19-33, 2014. Acesso em 22 mar. 2018 Disponível em: http://www.periodicos. ufpb.br/ojs/index.php/pgc/article/view/17897.

SILVA, A. K. A.; MOREIRA, E. C. B.; MONTEIRO, S. A. Gestão da informação: das origens aos modelos conceituais. In: DUARTE, E. N.; LLARENA, R. A. S.; LIRA, S. L. (Orgs.). Da informação à auditoria de conhecimento: a base para a Inteligência Organizacional. João Pessoa: Editora da UFPB, 2014. cap. 7, p. 237-268.

SILVA, P. A. da. Gestão de documentos, informação e conhecimento: a óptica dos gestores do serviço nacional de aprendizagem comercial (SENAC-DF). 2011. 159 f. Dissertação (Mestrado em Ciência da Informação). Universidade de Brasília, Brasília, DF, Brasil, 2011. Disponível em: http:// repositorio.unb.br/handle/10482/9448. Acesso em 22 mar. 2018.

TARAPANOFF, K. Informação, conhecimento e inteligência em corporações. In: (Org.). Inteligência, informação e conhecimento (p. 19-35). Brasília: IBICT, 2006.

VITORIANO, M. C de C. P. (2017). A relação entre gestão da informação e gestão documental na Arquivologia: mapeamento do tema em publicações científicas brasileiras. Palabra Clave (La Plata), v. 7, (1), p. 1-17. Disponível em: < http://www.redalyc.org/articulo.oa?id=350553375013> Aceso em: 22 mar. 2018. 